\section{Progression of Organ Involvement in Systemic Sclerosis Patients with Persistent "Late" Nailfold Capillaroscopic Pattern of Microangiopathy: A Prospective Study}

\section{To the Editor:}

Systemic sclerosis (SSc) is a complex systemic connective tissue disease characterized by vasculopathy and progressive fibrosis of skin and internal organs.

Peripheral microangiopathy is a dynamic event characterized by progressive capillary loss. Its advanced stage is depicted by the "late" nailfold videocapillaroscopy (NVC) pattern of microvascular damage ${ }^{1}$.

It has been reported that the decreased number of capillaries is associated with clinical subsets and the severity of SSc clinical complications ${ }^{2,3,4,5}$.

We performed a study to assess, to our knowledge for the first time, possible correlations between absolute nailfold capillary number $(\mathrm{CN})$ and organ involvement, in a cohort of SSc patients with the "Late" NVC pattern of microangiopathy diagnosed at baseline and during a followup of 5 years.

Twenty-three patients ( 22 women, mean age $64.30 \pm 12.38$ SD yrs, mean disease duration $7.74 \pm 7.61 \mathrm{yrs}$, mean Raynaud phenomenon duration 17.87 $\pm 15.35 \mathrm{yrs})$ affected by SSc according to the American College of Rheumatology/European League Against Rheumatism criteria and displaying the "Late" NVC pattern at baseline were recruited and followed for 5 years 6 .

All the patients gave written informed consent to enter the study. Ethics committee approval was not required for this type of noninvasive diagnostic tool (in accordance with the policy of our institution). During the followup, patients were receiving a wide range of drugs, including vasodilators (20 patients), cyclophosphamide (3), cyclosporine (8), methotrexate (4), mycophenolate (5), endothelin receptor antagonists (12), phosphodiesterase type 5 inhibitors (5), and aspirin (14).

To assess organ involvement, these procedures were performed annually: esophageal manometry, pulmonary function tests with DLCO, chest radiograph, lung computed tomography scan, electrocardiography, Doppler echocardiography with systolic pulmonary arterial pressure (PAP) measurement, and echo color Doppler with renal arterial resistive index (RI) measurement. Cardiac catheterization was performed in patients with Doppler echocardiography-estimated PAP $>40 \mathrm{mmHg}$ to confirm the diagnosis of pulmonary arterial hypertension (PAH). Presence of new digital ulcers (DU) was assessed, as well as cumulative DU number per year ${ }^{7}$. Skin involvement was assessed by modified Rodnan skin score (mRSS) to classify patients with SSc as affected by either limited (lcSSc) or diffuse (dcSSc) cutaneous $\mathrm{SSc}^{8}$.

NVC was performed to identify SSc patients with the "Late" pattern of microangiopathy, and to calculate the microangiopathy evolution score (MES) ${ }^{9,10}$. Absolute $\mathrm{CN}$ was also calculated according to standardized methods ${ }^{10}$
At baseline, 21 patients showed lcSSc (91\%), 2 dcSSc (9\%), 9 DU (39\%), 17 esophageal dysmotility (74\%), 11 interstitial lung disease (ILD; $48 \%$ ), and 2 renal involvement (9\%). No patients displayed PAH and/or heart involvement. In addition, 9 patients were found positive for anticentromere (ACA), 10 for anti-Scl-70, and 1 for anti-RNA polymerase III antibodies. At the end of 5 years of followup, 15 patients showed 1cSSc (65\%), 8 dcSSc (35\%), 11 new DU (48\%), 21 esophageal dysmotility (91\%), 22 ILD (96\%), and 5 renal involvement (22\%). Finally, 2 patients showed PAH (9\%) and 3 showed heart involvement (13\%; Table 1).

A progressive statistically significant decrease in $\mathrm{CN}(\mathrm{p}<0.0001)$, forced vital capacity (FVC; $\mathrm{p}=0.0001)$, and DLCO $(\mathrm{p}<0.0001)$ values was observed from baseline to 5 years, as well as a progressive statistically significant increase in renal arterial RI ( $p<0.0001)$, total DU $(p<0.0001)$, mRSS ( $p=0.0024)$, and MES ( $p=0.01$; Friedman test; Table 2). PAP was found significantly increased only at 5 years compared to basal values ( $\mathrm{p}=$ 0.03 ; Wilcoxon test).

Interestingly, the decrease in $\mathrm{CN}$ positively correlated over time with the worsening of FVC and DLCO values $(r=1, p=0.02 ; r=0.94, p=0.03$, respectively), and negatively correlated with the increase in renal arterial $\mathrm{RI}(\mathrm{r}=-0.91, \mathrm{p}=0.03)$, renal and heart involvement $(\mathrm{r}=-0.97, \mathrm{p}=0.03$ for both), total DU number $(r=-1, p=0.02)$, PAP values $(r=-0.94$, $\mathrm{p}=0.03)$, and MES $(\mathrm{r}=-0.83, \mathrm{p}=0.05)$. No difference regarding the mean $\mathrm{CN}$ was noted between patients with ACA and anti-Scl-70 positivity.

Our present study reports for the first time, to our knowledge, on patients with SSc in the context of the "Late" NVC pattern of microangiopathy, an association between progressive decrease of absolute $\mathrm{CN}$ and organ involvement during a 5-year followup, despite different treatments.

It is known that the "Late" NVC pattern represents a bad prognostic factor and a marker of an SSc subset with worse prognosis ${ }^{1,4,5}$, but it was not yet known what happens inside an SSc population with the constant "Late" pattern of microangiopathy.

The small sample size is one limitation of our study. This limitation was related to the inclusion criterion to enroll only SSc patients with "Late" NVC pattern of microangiopathy and with a recorded complete medical history and at least 5 years of followup. Further, this was an observational study to follow the progression of SSc damage in a selected cohort of patients, not considering possible effects of ongoing therapies.

Our investigation reports a progressive decrease of the absolute $\mathrm{CN}$ in advanced stages of the disease, which significantly correlates with progressive SSc organ involvement.

\section{ACKNOWLEDGMENT}

Dr. Sara De Gregorio from the Division of Rheumatology, University of Genoa, supported data processing and table processing.

Table 1. No. patients (\%) with different SSc subset and organ involvement at different times during the followup.

\begin{tabular}{lccccccc}
\hline & T0 & T1 & T2 & T3 & T4 & T5 & $\mathrm{p}^{*}$ \\
\hline lcSSc & $21(91)$ & $21(91)$ & $18(78)$ & $17(74)$ & $15(65)$ & $15(65)$ & 0.0004 \\
dcSSc & $2(9)$ & $2(9)$ & $5(22)$ & $6(26)$ & $8(35)$ & $8(35)$ & 0.0004 \\
New DU & $9(39)$ & $5(22)$ & $8(35)$ & $8(35)$ & $8(35)$ & $11(48)$ & $\mathrm{ns}$ \\
ED & $17(74)$ & $19(83)$ & $20(87)$ & $21(91)$ & $21(91)$ & $21(91)$ & 0.014 \\
ILD & $11(48)$ & $15(65)$ & $18(78)$ & $18(78)$ & $22(96)$ & $22(96)$ & $<0.0001$ \\
Kidney & $2(9)$ & $2(9)$ & $4(17)$ & $4(17)$ & $5(22)$ & $5(22)$ & 0.019 \\
PAH & $0(0)$ & $0(0)$ & $0(0)$ & $1(4)$ & $2(9)$ & $2(9)$ & $\mathrm{ns}$ \\
Heart & $0(0)$ & $0(0)$ & $1(4)$ & $2(9)$ & $3(13)$ & $3(13)$ & 0.044 \\
\hline
\end{tabular}

$\mathrm{T} 0=$ baseline, $\mathrm{T} 1=1$ year, $\mathrm{T} 2=2 \mathrm{yrs}, \mathrm{T} 3=3 \mathrm{yrs}, \mathrm{T} 4=4 \mathrm{yrs}, \mathrm{T} 5=5 \mathrm{yrs}$. $\mathrm{p}^{*}$ : statistical significance (Friedman test). SSc: systemic sclerosis; lcSSc: limited cutaneous SSc; dcSSc: diffuse cutaneous SSc; DU: digital ulcers; ED: esophageal dysmotility; ILD: interstitial lung disease; PAH: pulmonary arterial hypertension (diagnosed by right-heart cardiac catheterization); ns: not statistically significant. 
Table 2. Mean \pm SD of clinical variables at different times during the 5-year followup and statistical analysis between single times.

\begin{tabular}{|c|c|c|c|c|c|c|c|}
\hline & T0 & $\mathrm{T} 1$ & $\mathrm{~T} 2$ & $\mathrm{~T} 3$ & $\mathrm{~T} 4$ & T5 & $\mathrm{p}^{*}$ \\
\hline $\mathrm{CN}$ & $5.40 \pm 0.99$ & $4.95 \pm 1.13$ & $4.68 \pm 1.17$ & $4.40 \pm 1.26$ & $4.32 \pm 1.24$ & $4.23 \pm 1.21$ & $<0.0001$ \\
\hline MES & $6.00 \pm 1.21$ & $6.30 \pm 1.40$ & $6.52 \pm 1.12$ & $6.74 \pm 1.18$ & $6.57 \pm 1.31$ & $6.65 \pm 1.27$ & 0.01 \\
\hline DLCO/VA & $83.26 \pm 13.30$ & $80.30 \pm 14.79$ & $74.96 \pm 16.81$ & $72.70 \pm 17.80$ & $70.48 \pm 17.77$ & $71.17 \pm 14.21$ & $<0.0001$ \\
\hline RI & $0.66 \pm 0.07$ & $0.66 \pm 0.06$ & $0.68 \pm 0.07$ & $0.70 \pm 0.07$ & $0.70 \pm 0.07$ & $0.72 \pm 0.07$ & $<0.0001$ \\
\hline Total DU & $0.70 \pm 0.97$ & $1.00 \pm 1.45$ & $1.48 \pm 1.97$ & $2.00 \pm 2.61$ & $2.61 \pm 3.20$ & $3.30 \pm 3.71$ & $<0.0001$ \\
\hline
\end{tabular}

$\mathrm{T} 0=$ baseline, $\mathrm{T} 1=1$ year, $\mathrm{T} 2=2 \mathrm{yrs}, \mathrm{T} 3=3 \mathrm{yrs}, \mathrm{T} 4=4 \mathrm{yrs}, \mathrm{T} 5=5 \mathrm{yrs} . \mathrm{p} *$ : statistical significance (Friedman test). CN: nailfold capillary no./mm $($ distal row); MES: microangiopathy evolution score (range 0-9); FVC: forced vital capacity (\% predicted, normal values > 80); DLCO/VA: DLCO per unit of lung volume (\% predicted, normal values $>75$ ); RI: renal arterial resistive index (normal values $<0.70$ ); DU: digital ulcers; sPAP: echo-estimated systolic pulmonary arterial pressure (limit for cardiac catheterization $>40 \mathrm{mmHg}$ ); mRSS: modified Rodnan skin score; ns: not statistically significant.

CARMEN PIZZORNI, MD, PhD, Assistant Professor of Rheumatology, Research Laboratory and Academic Division of Clinical Rheumatology, Department of Internal Medicine, University of Genoa, IRCCS San Martino; ALBERTO SULLI, MD, Associate Professor of Rheumatology, Research Laboratory and Academic Division of Clinical Rheumatology, Department of Internal Medicine, University of Genoa, IRCCS San Martino; SABRINA PAOLINO, MD, Assistant Professor of Rheumatology, Research Laboratory and Academic Division of Clinical Rheumatology, Department of Internal Medicine, University of Genoa, IRCCS San Martino; BARBARA RUARO, MD, PhD, Fellow in Rheumatology Division, Research Laboratory and Academic Division of Clinical Rheumatology, Department of Internal Medicine, University of Genoa, IRCCS San Martino, Genoa, Italy; VANESSA SMITH, MD, PhD, Associate Professor of Rheumatology, Department of Rheumatology, Ghent University Hospital, Ghent, Belgium; AMELIA CHIARA TROMBETTA, MD, PhD, Trainee in Clinical and Experimental Immunology, Research Laboratory and Academic Division of Clinical Rheumatology, Department of Internal Medicine, University of Genoa, IRCCS San Martino; MAURIZIO CUTOLO, MD, Professor of Rheumatology, Research Laboratory and Academic Division of Clinical Rheumatology, Department of Internal Medicine, University of Genoa, IRCCS San Martino, Genoa, Italy. V. Smith is a Senior Clinical Investigator of the Research Foundation Flanders, Brussels, Belgium (FWO) [1802915N]. C. Pizzorni, M. Cutolo, B. Ruaro, V. Smith, and A. Sulli are members of the European League Against Rheumatism Study Group on Microcirculation in Rheumatic Diseases. Address correspondence to Dr. M. Cutolo, Research Laboratory and Academic Division of Clinical Rheumatology, Department of Internal Medicine, University of Genoa, Viale Benedetto XV, no. 6, 16132 Genoa, Italy.E-mail: mcutolo@unige.it

\section{REFERENCES}

1. Cutolo M, Sulli A, Smith V. Assessing microvascular changes in systemic sclerosis diagnosis and management. Nat Rev Rheumatol 2010;6:578-87.

2. Cutolo M, Herrick AL, Distler O, Becker MO, Beltran E, Carpentier
P, et al; CAP Study Investigators. Nailfold videocapillaroscopic features and other clinical risk factors for digital ulcers in systemic sclerosis: a multicenter, prospective cohort study. Arthritis Rheumatol 2016;68:2527-39.

3. Trombetta AC, Pizzorni C, Ruaro B, Paolino S, Sulli A, Smith V, et al. Effects of longterm treatment with bosentan and iloprost on nailfold absolute capillary number, fingertip blood perfusion, and clinical status in systemic sclerosis. J Rheumatol 2016;43:2033-41.

4. Sulli A, Pizzorni C, Smith V, Zampogna G, Ravera F, Cutolo M. Timing of transition between capillaroscopic patterns in systemic sclerosis. Arthritis Rheum 2012;64:821-5.

5. Smith V, Decuman S, Sulli A, Bonroy C, Piettte Y, Deschepper E, et al. Do worsening scleroderma capillaroscopic patterns predict future severe organ involvement? A pilot study. Ann Rheum Dis 2012;71:1636-9.

6. Van den Hoogen F, Khanna D, Fransen J, Johnson SR, Baron M, Tyndall A, et al. 2013 classification criteria for systemic sclerosis: an American College of Rheumatology/European League against Rheumatism collaborative initiative. Arthritis Rheum 2013; 65:2737-47.

7. Reed J, Pope J. A comparison between general rheumatologists and scleroderma experts with respect to following systemic sclerosis guidelines. Clin Exp Rheumatol 2015;33 Suppl 91:S40-6.

8. LeRoy EC, Black C, Fleischmajer R, Jablonska S, Krieg T, Medsger TA Jr, et al. Scleroderma (systemic sclerosis): classification, subsets and pathogenesis. J Rheumatol 1988;15:202-5.

9. Sulli A, Secchi ME, Pizzorni C, Cutolo M. Scoring the nailfold microvascular changes during the capillaroscopic analysis in systemic sclerosis patients. Ann Rheum Dis 2008;67:885-7.

10. Cutolo M, Sulli A, Pizzorni C, Accardo S. Nailfold videocapillaroscopy of microvascular damage in systemic sclerosis. J Rheumatol 2000;27:155-60.

J Rheumatol 2017;44:12; doi:10.3899/jrheum.170485 